\title{
Process modelling of seasonal hot water supply heliosystem
}

\author{
Yevgeniy Umerenkov ${ }^{1}$, Elina Umerenkova ${ }^{1,{ }^{*}}$, Ekaterina Pakhomova ${ }^{1}$, and Natalia \\ Semicheva ${ }^{1}$ \\ ${ }^{1}$ Southwest State University, 94, 50 let Oktyabrya, 305040, Kursk, Russia
}

\begin{abstract}
A variant of the problem statement is proposed to develop an algorithm for calculating a solar collector of hot water supply for an individual dwelling. The purpose of the calculations is to determine the approximate values of the main characteristics of the heliosystem of hot water supply, which affect the technical and economic indicators of the system and determine the operating mode of the system, its comfort in use and maintenance.
\end{abstract}

\section{Introduction}

Posing the question of an energy efficiency improvement of the engineering systems and energy saving [1] leads, inter alia, to an enquiry into the possibility and feasibility of using renewable energy sources.

Heat supply systems which are using traditional types of heat energy and alternative heat power engineering using solar and other renewable types of energy, as well as waste energy recovery used for purposes of heat supply of residential, public and industrial buildings, as a rule, provide for the storage of excess heat energy [2-6].

The matters of economic feasibility of using solar heating systems were considered in papers [7-9]. It is obvious that the analysis of the possibility and feasibility of using an energy saving equipment, namely, the solar heating systems in an individual dwelling cannot be performed in isolation from the specific geographical location of an object.

The paper [10] has considered a possibility of seasonal use of the solar heating system to provide hot water for an individual dwelling located in the rural areas of the Kursk region. The geography of the location of the object in this case determines a relatively low (compared with the Southern regions of the country) level of solar radiation intensity and the presence of low, negative temperatures in winter (up to $30^{\circ} \mathrm{C}$ ), which creates significant difficulties during the full-time basis operation of the system.

The basis for the development of the engineering calculating methods of the heat accumulators is an approximate model to formulate the heat transfer problem $[4,5,11,12]$.

In the present work an attempt is made to develop a simplified approach for further algorithmization of the calculation of a hot water solar collector for an individual residential building and to identify the main predicted values.

\footnotetext{
* Corresponding author: elinaelya@gmail.com
} 


\section{Experimental}

The object is a solar system of hot water supply, which includes the entire solar circuit and some elements of the water supply circuit: a storage tank, a make-up system and a take-off pipe.

Under discussion two circuits are used in the solar system of hot water supply [10], which is due to the following factors:

- the solar system of hot water supply is combined with the heating system, and the use of a hot water heater of a "winter" hot water supply system reduces the cost and simplifies the system as a whole;

- in the developed scheme, the heating agent (coolant) circulates through the solar circuit, which is depleted in air (as compared with tap water, which would flow to the collecting box under an open circuit), which has been released during the off hours through the expansion tank; this leads to a decrease in corrosion of both pipes and collectors, and the heat exchanger coil, and besides there is no constant (during the working period) encrustation of pipes due to salt precipitation;

- during the system operation with a closed solar circuit, it is possible to fill it with antifreeze agent which allows to extend the calendar terms of using the system without additional labor costs; pilot runs and shutdowns of the system are also possible without emptying the storage tank.

The purpose of the engineering calculation problem of a hot water solar collector for an individual dwelling is to determine the approximate values of the main characteristics that affect the technical and economic indicators of the system and define the system operation condition, its comfort in use and maintenance.

As a performance criterion, the substitution coefficient, $\mathrm{f}$, of the solar system of hot water supply is adopted. It corresponds to a value equal to the share of the heat duty of hot water supply satisfied by the absorbed solar energy during the operating period of the installation (6 months).

In addition, the goal is to determine the following values:

- efficiency factor of a solar station i.e. the solar fraction which is incident on the surface of the solar heat collectors, which has been absorbed and usefully used;

- the total cost to heat the water up in the stand-by (replacement) heaters, for the pump drive and the automation system $\left(Q_{\text {add }}^{\text {gen }}\right)$;

- variation of the water temperature in the storage tank according to the design (average) days of the months during operation activity of solar hot water supply system, which characterizes the comfort of the system, and the determination of the time for additional water treatment before water draw-off as well as the time of heating it up $\left(t_{A}\right)$.

The problem statement involves a description of the following basic processes:

- absorption of solar energy by solar heat collectors;

- heating of the coolant in the solar heat collectors;

- cooling of the coolant in the tube coil of the storage tank;

- thermal transfer from the coolant of the solar circuit to the water through the heating surface of the tube coil of the storage tank;

- water heating (cooling) in the storage tank under the influence of the following factors: tube coil heat transfer; stand pipe heat loss; hot water take-off; cold water supply.

The water heating process in an electric water heater is not considered in this paper, but it is implied. 


\section{Evaluation}

The operation of the solar hot water supply system is characterized by non-steady processes of heat and mass transfer, which creates certain difficulties for describing them by mathematical equations.

Therefore, when developing a mathematical model, several assumptions, justified in [8], were introduced, which do not significantly affect the final result. Some assumptions will be analyzed during the model preparation.

The power absorbed in the solar heat collectors can be found using the formula [7]:

$$
Q_{k}=F_{R} \cdot A \cdot\left[E(\tau) \cdot(\tau \cdot \alpha)-\mho_{L} \cdot\left(t_{k}^{\prime}-t_{H}\right)\right], \mathrm{W}
$$

where:

$F_{R}$ - the coefficient of heat transfer from the collector;

$A$ - surface area of the absorber plates of solar collectors, $\mathrm{m}^{2}$;

$E(\tau)$ - solar radiation flux in the plane of solar collectors, $\mathrm{W} / \mathrm{m}^{2}$;

$\tau$ - throughput capacity of the transparent cover of the solar heat collector in relation to solar radiation, depending on the angle of the incidence of sunlight;

$\alpha$ - absorption capacity of the collector plate with respect to solar radiation, depending on the angle of the incidence of sunlight;

$U_{L}$ - total coefficient of heat losses of the solar heat collector, $\mathrm{W} /\left(\mathrm{m}^{2} \cdot{ }^{\circ} \mathrm{C}\right)$;

$t_{k}^{\prime}$ - coolant temperature of the solar circuit at the inlet of the solar heat collector, ${ }^{\circ} \mathrm{C}$;

$t_{H}$ - outdoor temperature, ${ }^{\circ} \mathrm{C}$;

Power absorbed by the coolant and removed from the solar heat collector:

$$
Q_{\mathrm{K}}^{\prime \prime}=A \cdot G_{K} \cdot C_{p k} \cdot\left(t_{k}^{\prime \prime}-t_{k}^{\prime}\right), W
$$

$G_{K}$ - coolant flow in the solar circuit per $1 \mathrm{~m}^{2}$ of the surface of the solar heat collector, $\mathrm{kg} /\left(\mathrm{s} \cdot \mathrm{m}^{2}\right)$;

$C_{p k}$ - specific heat capacity of coolant of the solar circuit, $\mathrm{J} /\left(\mathrm{kg}{ }^{\circ} \mathrm{C}\right)$;

$t_{k}^{\prime \prime}$ - coolant temperature of the solar circuit at the output of the solar heat collector, ${ }^{\circ} \mathrm{C}$;

Capacity given by the solar circuit coolant in the tube coil of the storage tank:

$$
Q_{A}^{\prime}=G_{K} \cdot A \cdot C_{p k} \cdot\left(t_{A}^{\prime}-t_{k}^{\prime \prime}\right), W
$$

where:

$t_{A}^{\prime}-t_{k}^{\prime \prime}$ - coolant temperature of the solar circuit respectively at the inlet and output of the tube coil of the storage tank, ${ }^{\circ} \mathrm{C}$;

Power transmitted through the heating surface of the tube coil of the storage tank:

$$
Q_{A}^{\prime \prime}=R_{A} \cdot F_{A} \cdot \Delta \bar{t}, W
$$

where:

$R_{A}$ - coil heat transfer coefficient, $\mathrm{W} /\left(\mathrm{m}^{2}{ }^{\circ} \mathrm{C}\right)$;

$F_{A}$ - heating surface area of the coil on the basis of which the value of $R_{A}, \mathrm{~m}^{2}$ has been defined;

$\Delta \bar{t}$ - the average temperature drop created on the tube coil between the coolant of the solar circuit and the water in the storage tank, ${ }^{\circ} \mathrm{C}$. 
The heat balance equation for a storage tank:

$$
Q_{A}^{\prime \prime}+Q_{c}=Q_{v}+Q_{g v}+Q_{l o s}, \mathrm{~W}
$$

where:

$Q_{c}$ - heat amount entering the storage tank when it is fed with cold water, $\mathrm{W}$, defined by the formula (6);

$Q_{v}$ - heat amount spent on changing the heat supply of water in the storage tank, W, defined by the formula (7) (positive with rising temperature, negative with decreasing);

$Q_{g v}$ - heat amount removed from the storage tank during water draw-off, W, calculated using the formula (8);

$Q_{\text {los }}$ - heat loss of the storage tank, W, calculated using the formula (9);

that is:

$$
\begin{aligned}
& Q_{c}=G_{a} \cdot G_{p k} \cdot t_{c}, \mathrm{~W} \\
& Q_{v}=M \cdot G_{p k} \cdot \frac{d \bar{t}_{a}}{d \tau}, \mathrm{W} \\
& Q_{g v}=G_{A} \cdot G_{p k} \cdot t_{a^{*}}, \mathrm{~W} \\
& Q_{l o s}=R_{b} \cdot F_{b} \cdot\left(\overline{t_{a}}-t_{H^{*}}\right), \mathrm{W}
\end{aligned}
$$

where:

$G_{a}$ - water flow through the storage tank, determined by the water consumption mode, $\mathrm{kg} / \mathrm{s}$

$t_{c}$ - temperature of the water coming from cold water pipeline, ${ }^{\circ} \mathrm{C}$

$\tau$ - time, c;

$\overline{t_{a}}$ - average integral temperature of the water in the storage tank;

$M$ - volume of the water supply stored in the storage tank, $\mathrm{kg}$;

$t_{a^{*}}$ - water temperature in the storage tank in the water draw-off zone by a water supply pipeline, ${ }^{\circ} \mathrm{C} ; F_{b}$

$F_{b}$ - the surface area of the walls of the storage tank, $\mathrm{m}^{2}$;

$R_{b}$ - heat transfer coefficient through the walls of the storage tank, $\mathrm{W} /\left(\mathrm{m}^{2}{ }^{\circ} \mathrm{C}\right)$;

$t_{H^{*}}$ - air temperature in the place where the storage tank is installed, ${ }^{\circ} \mathrm{C}$;

The temperature of the absorber plate of the solar heat collector in the absence of a circulating coolant (there is no heat transfer) can be defines by the formula: ([13])

$$
t_{\infty}=t_{H}+\frac{E(\tau) \cdot(\tau \alpha)}{U_{L}},{ }^{\circ} \mathrm{C}
$$

where all values correspond to the notation in the formula (1).

It should be noted that an equation (1) is written for one solar heat collector. To determine the total heat input, it is necessary to summarize the results obtained by calculating each collector separately. But, neglecting the insignificant quantity of the uneven distribution of the coolant in the collectors and the heat loss in the connecting pipelines, we can consider the solar heat collector unit as a single panel, the area of which is equal to the sum of the areas that make up the solar collector unit. In this case, the heat balance equation for solar heat collectors is written in the following formula:

$$
Q_{K}^{\prime}=Q_{K}^{\prime \prime}, \mathrm{W}
$$

The heat balance equation for the coil of the storage tank: 


$$
Q_{A}^{\prime}=Q_{A}^{\prime \prime}, \mathrm{W}
$$

Neglecting the heat losses of the pipelines of the solar circuit, it could be written:

$$
Q_{K}^{\prime}=Q_{A}^{\prime \prime}, \mathrm{W}
$$

When the system is operating in the solar energy storage mode (with and without water draw-off), a constant natural water circulation will be observed in the storage tank due to the lower layer heating of the coil. At the same time, an approximately constant temperature is established throughout the volume, since a stratification is not provided by the project. The occurrence of a temperature gradient is possible only when there is no heat supply from the solar heat collectors $\left(t_{\infty} \leq t_{A}\right)$. However, neglecting this stratification of water, we will obtain a slightly erroneously low result (about the system efficiency), but with a small error. Considering this assumption, it is possible to accept water temperature in the tank as fixed throughout the volume at any given time:

$$
t_{a^{*}}=t_{a} \overline{t_{a}},{ }^{\circ} \mathrm{C}
$$

The average temperature drop on the coil (see a formula (4) with sufficient accuracy can be taken as equal to the arithmetic mean at any time, that is

$$
\Delta \bar{t}=\frac{t_{A}^{\prime}+t_{A}^{\prime \prime}}{2}-t_{A},{ }^{\circ} \mathrm{C}
$$

Thus, the equations (11), (13)-(15) have written down all agreed hypotheses which are accepted to simplify the mathematical model and its calculations.

Modeling of unsteady thermal processes is always associated with difficulties in the preparation and solution of balance equations. Therefore, in [8], it is recommended to model unsteady processes as steady processes for a certain period of time. When modeling solar systems (heliosystems), the main source data to calculate heat transfer are relatively piecewise constant functions of the intensity value of solar radiation and outdoor temperature. At the initial moment of the time interval $\Delta \tau$, external conditions are determined and the thermal balance of the system is considered.

The application of this principle and modeling gives good results ([14]). Therefore, it was applied in this work. We rewrite equation (13) taking into account (2) and (3).

$$
\begin{gathered}
A \cdot G_{A} \cdot C_{p k} \cdot\left(t_{K}^{\prime \prime}-t_{K}^{\prime}\right)=A \cdot G_{A} \cdot C_{p k} \cdot\left(t_{A}^{\prime}-t_{A}^{\prime \prime}\right), \\
t_{K}^{\prime \prime}-t_{K}^{\prime}=t_{A}^{\prime}-t_{A}^{\prime \prime}
\end{gathered}
$$

Having considered the fact that all four temperatures in equation (17) characterize the same coolant at different points of the system, and assuming that the process is steady, we get the only solution:

$$
\left\{t_{K}^{\prime \prime}-t_{A}^{\prime} ; t_{A}^{\prime \prime}-t_{K}^{\prime}\right.
$$

That is, the coolant's temperature of the solar circuit changes only in the solar heat collectors and in the coil of the storage tank, remaining constant throughout the entire pipelines of the circuit.

To generate an equation by solving which it would be possible to find the basic predicted values $\left(t_{A}\right)$ and $Q_{a d d}^{g e n}$ (the variation of the water temperature in the storage tank and the total amount of additional energy, it is necessary to solve equations (5), (11) and (12) taking into account (14), (15) and (18): 


$$
\begin{gathered}
R_{A} \cdot F_{A} \cdot\left(\frac{t_{K}^{\prime \prime}+t_{K}^{\prime}}{2}-t_{A}\right)+G_{A} \cdot C_{p k} \cdot t_{x} \\
=M \cdot C_{p k} \cdot \frac{d t_{A}}{d \tau}+G_{A} \cdot C_{p k} \cdot t_{A}+R_{b} \cdot F_{b} \cdot\left(t_{A}-t_{H^{*}}\right) \\
A \cdot F_{R} \cdot(\tau \alpha) \cdot E-A \cdot F_{R} \cdot U_{L} \cdot\left(t_{K}^{\prime}-t_{H}\right)=A \cdot G_{A} \cdot C_{p k} \cdot\left(t_{K}^{\prime \prime}-t_{K}^{\prime}\right), \mathrm{W} \\
\left.A \cdot G_{A} \cdot C_{p k} \cdot\left(t_{K}^{\prime \prime}-t_{K}^{\prime}\right)=R_{A} \cdot F_{A} \cdot\left(\frac{t_{K}^{\prime}+t_{K}^{\prime \prime}}{2}\right)-t_{A}\right), \mathrm{W}
\end{gathered}
$$

It is more convenient to use the equation (20) after carrying out some transformations:

$$
F_{R} \cdot(\tau \alpha)_{n} \cdot \frac{(\tau \alpha)}{(\tau \alpha)_{n}} \cdot E-F_{R} \cdot U_{L} \cdot\left(t_{K}^{\prime}-t_{H}\right)=G_{A} \cdot C_{p k} \cdot\left(t_{K}^{\prime \prime}-t_{K}^{\prime}\right)
$$

Here $(\tau \alpha)_{n}$ is the optical efficiency of the solar collector in relation to solar radiation which is incident on the surface normally.

The values $F_{R} \cdot(\tau \alpha)_{n}$ and $F_{R} \cdot U_{L}$ characterize the structural design of solar heat collectors and are determined by their sizes and devices. These values are determined during thermal tests and are recorded into the collector's passport.

Having entered some notations it is possible to simplify considerably the recording of the equations (19), (21) and (22). Further the following designations are used:

$$
\left\{\begin{array}{c}
X=F_{R}(\tau \alpha)_{n} ; Y=F_{R} \mho_{L} ; \beta=\frac{\tau \alpha}{(\tau \alpha)_{n}} ; m_{a}=M \cdot C_{p a} \\
f_{a}=F_{R} \cdot F_{A} ; f_{b}=R_{b} \cdot F_{b} ; g_{a}=G_{A} \cdot C_{p a} ; g_{k}=G_{K} \cdot C_{p k}
\end{array}\right.
$$

Taking into account the introduced notations and omitting the intermediate transformations, we obtain:

$$
\left\{\begin{array}{c}
f_{a} \cdot\left(\frac{t_{K}^{\prime}+t_{K}^{\prime \prime}}{2}\right)+g_{a} \cdot t_{x}=m_{a} \cdot \frac{\alpha t_{a}}{\alpha \tau}+g_{a} t_{a}+f_{b}\left(t_{A}-t_{H *}\right) \\
A \cdot g_{k} \cdot\left(t_{K}^{\prime \prime}+t_{K}^{\prime}\right)=f_{a} \cdot\left(\frac{t_{K}^{\prime}+t_{K}^{\prime \prime}}{2}-t_{A}\right) \\
x \cdot \beta \cdot E-Y \cdot\left(t_{K}^{\prime}-t_{H}\right)=g_{k} \cdot\left(t_{K}^{\prime \prime}-t_{K}^{\prime}\right)
\end{array}\right.
$$

In the equations (24) - (26), the unknown quantities are $t_{A} ; t_{K}^{\prime}$ and $t_{K}^{\prime \prime}$, i.e. there are three equations with three unknown quantities. To solve the system, first of all, it is necessary to obtain an analytic expression for finding $t_{A}$.

$$
t_{K}^{\prime}=\frac{f_{a} \cdot t_{A}+X \cdot \beta\left(A-\frac{f_{a}}{2 \cdot g_{k}}\right) \cdot E+Y\left(A-\frac{f_{a}}{2 \cdot g_{k}}\right) \cdot t_{H}}{A \cdot Y+f_{a}-\frac{f_{a} \cdot Y}{2 \cdot g_{k}}}
$$

Having done some transformations, we obtain an equation that is solvable with respect to $t_{A}$ and which does not include $t_{K}^{\prime}$ and $t_{K}^{\prime \prime}$ :

$$
\frac{\alpha t_{A}}{\alpha \tau}+\frac{1}{m_{a}} \cdot\left(g_{a}+f_{b}+\frac{A \cdot Y+f_{a}}{A \cdot Y+f_{a}-\frac{f_{a} \cdot Y}{2 \cdot g_{k}}}\right)=\frac{1}{m_{a}} \frac{A \cdot X \cdot \beta \cdot f_{a}}{A \cdot Y+f_{a}-\frac{f_{a} \cdot Y}{2 \cdot g_{k}}} E
$$




$$
+\frac{1}{m_{a}} \frac{\mathrm{A} \cdot Y \cdot f_{a}}{A \cdot Y+f_{a}-\frac{f a \cdot Y}{2 \cdot g_{k}}} \cdot t_{H+} \frac{f_{b}}{m_{a}} t_{H^{*}}+\frac{g_{a}}{m_{a}} t_{x}
$$

The equation (28) includes the value $t_{H^{*}}$ that is the room temperature where the storage tank is installed. It is difficult to determine with sufficient accuracy the dependence of $t_{H *}$ on $t_{H}, \mathrm{E}$ and other factors. It is arguable that in the mean $t_{H^{*}}$ is not lower than $t_{H}$, and since, heat $Q_{\text {los }}$ from the storage tank enters the room, so $t_{H^{*}}>t_{H}$.

In the calculations it was assumed that the temperature difference is constant and equal to $5{ }^{\circ} \mathrm{C}$, a more accurate estimate is possible after determining $\left(t_{A}\right)$. Taking into account the above, we introduce new notations.

$$
\left\{\begin{array}{c}
a_{0}=\frac{1}{m_{a}} \cdot\left(g_{a}+f_{b}+\frac{A \cdot Y+f_{a}}{A \cdot Y+f_{a}-\frac{f_{a} \cdot Y}{2 \cdot g_{k}}}\right) \\
a_{1}=\frac{1}{m_{a}} \cdot\left(\frac{A \cdot X \cdot \beta+f_{a}}{A \cdot Y+f_{a}-\frac{f_{a} \cdot Y}{2 \cdot g_{k}}}\right) \\
a_{2}=\frac{1}{m_{a}} \cdot f_{b}+\left(\frac{A \cdot Y+f_{a}}{A \cdot Y+f_{a}-\frac{f_{a} \cdot Y}{2 \cdot g_{k}}}\right) \\
a_{3}=\frac{1}{m_{a}} \cdot\left(5 \cdot f_{b}+g_{a} \cdot t_{x}\right)
\end{array}\right.
$$

Taking into account introduced notations:

$$
\frac{\alpha t_{a}}{\alpha \tau}+a_{0} \cdot t_{A}=a_{1} \cdot E+a_{2} \cdot t_{H}+a_{3}
$$

According to the above mentioned, the values $E$ and $t_{H}$ are assumed relatively constant during the time interval $\Delta \tau=\tau-\tau_{0}$. Therefore, we can denote the right side of the equation (29) by means of some invariable:

$$
\mathrm{c}_{0}=a_{1} \cdot E+a_{2} \cdot t_{H}+a_{3}
$$

The equation (29) takes on a much simpler form:

$$
\frac{\alpha t_{a}}{\alpha \tau}+a_{0} \cdot t_{A}=\mathrm{c}_{0}
$$

Thus, having solved the system of equations (5), (11) and (12) with respect to $t_{A}$, we obtained a first-order linear differential equation with separable variables.

We solve this equation by the method of separation of variables, as the most common.

The initial condition has been chosen as follows: at the initial moment of the calculated time interval $\Delta \tau=\tau_{1}-\tau_{0}$, that is at $\tau=\tau_{0}=0$.

The water temperature in the tank is equal to the initial

$$
t_{A} / \tau_{0}=t_{A O}
$$

Having established the initial conditions, we obtain the partial solution of the equation (31) that interests us: 


$$
t_{A}=\left(t_{A O} \cdot \frac{c_{0}}{a_{0}}\right) \mathrm{e}^{-a_{0} \tau}+\frac{c_{0}}{a_{0}},{ }^{\circ} \mathrm{C}
$$

\section{Conclusions}

1. Thus, a universal equation has been obtained which allows to calculate the variation of the water temperature in the storage tank for any operating mode of the solar water supply system.

2. This also allows to calculate the main predicted parameters of the solar system.

\section{References}

1. N.G. Ganzha, A.V. Khimenko, Energosberezheniye. Energetika. Energoaudit 3(97), 16-21 (2012)

2. E.V. Kotenko, Razrabotka matematicheskikh modeley $i$ metodik rascheta akkumulyatornykh batarey na fazovom perekhode. Avtoref. dis. kand. tekhn. Nauk (Kursk, 1996)

3. Ye.V. Umerenkov, Razrabotka akkumulyatorov teplykh na fazovom perekhode dlya sistem teplosnabzheniya. Avtoref. dis. kand. tekhn. nauk (Kursk, 2013)

4. K.A. Gar'kavyy, Innovatsionnaya nauka 2-3(14), 29-30 (2016)

5. P.Y. Vede, Ye.V. Kiselkin, Epokha nauki 14, 165-173 (2018)

6. Y.M. Matsevityy, N.G. Ganzha, A.V. Khimenko, Energosberezheniye. Energetika. Energoaudit 10(92), 9-16 (2011)

7. A.V. Matveyev, S.Ye. Shcheklein, V.M. Pakhaluyev, Mezhdunarodnyy nauchnyy zhurnal Al'ternativnaya energetika i ekologiya 10-11, 56-62 (2015)

8. Y.V. Tsymbalyuk, M.V. Geras'kin, Nauchnyy zhurnal. Inzhenernyye sistemy i sooruzheniya 4-2(17), 71-75 (2014)

9. A.Y. Almayev, I.A. Lushkin, Vestnik NGIEI 12(43), 5-9 (2014)

10. E.V. Umerenkova, Ye.V. Umerenkov, M.D. Zayko, A.A. Shpil'ko, 8-aya Mezhdunarodnaya molodezhnaya nauchnaya konferentsii 3, 371-374 (2018)

11. V.N. Brovtsin, A.F. Erk, Tekhnologii i tekhnicheskiye sredstva mekhanizirovannogo proizvodstva produktsii rasteniyevodstva i zhivotnovodstva 84, 90-112 (2013) 